\title{
Efecto del consumo agudo de cafeína sobre la fuerza máxima y los niveles de lactato en sangre en jóvenes sedentarios: Ensayo clínico aleatorizado
}

\author{
Effect of acute caffeine consumption on the maximum force and blood lactate levels in sedentary young: \\ Randomized clinical trial
}

\section{Amy Andrea Arteaga-Sacro', Diego Fernando Villota-Bedoya²}

1 Fisioterapeuta, Magister en Bioquímica Clínica. Docente Universidad San Buenaventura. Cartagena, Colombia. e-mail: amy.andrea125@hotmail.com

2 Fisioterapeuta, Magister en Neurorehabilitación. Docente Universidad San Buenaventura. Cartagena, Colombia. e-mail: vigodie125@hotmail.com

\section{Resumen}

Objetivo: El propósito del estudio fue demostrar el efecto de la cafeína en consumo agudo sobre la fuerza máxima y los niveles de lactato. Material y métodos: Ensayo clínico aleatorizado controlado de grupos paralelos ciego simple (participante). Se seleccionaron 92 sujetos, 43 fueron asignados aleatoriamente al grupo de ingesta de cafeína (1,3 $\mathrm{mg} / \mathrm{Kg}$ ) o el control con placebo. Se utilizó el test de 1RM para medir la fuerza máxima y el lactato se determinó mediante espectrofotometría (Kit comercial Sigma) antes y después de 1 hora de la ingestión de cafeína $(1,3 \mathrm{mg} / \mathrm{Kg})$ o placebo. El análisis estadístico se realizó con la prueba t-student, el cambio porcentual y el tamaño del efecto con la d-Cohens, $p \leq 0,05$. Resultados: Se produjo una mejoraría significativa en la fuerza máxima de miembro superior de $1 \mathrm{RM} 8,3 \pm 6,0 \mathrm{~kg}$ con un tamaño efecto medio $(26,2 \% ; \mathrm{d}=0,64 ; \mathrm{t}=-4,36$; $\mathrm{gl}=41 ; \mathrm{p}<0,01 ; \mathrm{IC}:-16,9 \mathrm{a}-6,2)$; y de miembro inferior de $1 \mathrm{RM} 9,2 \pm 4,9 \mathrm{~kg}$ con un tamaño del efecto medio $(25,8 \%$; $=0,51 ; \mathrm{t}=-3,16 ; \mathrm{gl}=41 ; \mathrm{p}<0,01 ; \mathrm{IC}:-17,0$ a $-3,7)$. Para los niveles de lactato se observó un aumento menor en el grupo experimental 0,96 $\pm 0,10 \mathrm{mmol} / \mathrm{L}$ con un tamaño del efecto pequeño $(64,9 \% ; d=0,39 ; t=10,8 ; g l=41 ; p<0,01 ;$ IC: 0,55 a 0,81). Conclusiones: La cafeína en dosis baja produce un incremento superior en la fuerza máxima de miembro superior, seguido por la fuerza máxima de miembro inferior y favorece un incremento menor de los niveles de lactato.

Palabras clave: Cafeína; fuerza muscular; lactato; ejercicio. (Fuente: DeCS, Bireme).

\begin{abstract}
Objective: The aim of this study was to demonstrate the effect of caffeine in acute consumption on the maximum force and lactate levels. Material and methods: A randomized controlled trial of single-blind parallel group (participant) was done where 92 subjects were selected, 43 were assigned randomly to the caffeine intake group $(1,3 \mathrm{mg} / \mathrm{Kg}) \mathrm{or}$ placebo control. The 1RM test was used to measure the maximum force and the lactate was determined by spectrophotometry (Sigma Kit commercial) before and after an hour of caffeine intake $(1,3 \mathrm{mg} / \mathrm{Kg}$ ) or placebo. The statistical analysis was performed using the student t- test, and the percentage change and the effect size with Cohen's $\mathrm{d}-\mathrm{p} \leq 0.05$. Results: There was a significant improve in the maximum force of upper limb of $1 \mathrm{RM} 8.3 \pm 6.0 \mathrm{~kg}$ with an average effect size (26.2\%; $d=0.64, t=-4.36, d f=41, p<0.01 ; C I:-16.9$ to -6.2$)$; and lower limb $1 \mathrm{RM} 9.2 \pm 4.9 \mathrm{~kg}$ with
\end{abstract}


a medium effect size $(25.8 \% ; \mathrm{d}=0.51, \mathrm{t}=-3.16, \mathrm{df}=41, \mathrm{p}<0.01, \mathrm{CI}:-17.0$ to -3.7$)$. An increase in the lactate levels was observed in the experimental group $0.96 \pm 0.10 \mathrm{mmol} / \mathrm{L}$ with a small effect size $(64.9 \% ; \mathrm{d}=0,39 ; \mathrm{t}=10.8 ; \mathrm{gl}=41 ; \mathrm{p}$ \&lt; 0.01;) CI: 0.55 to 0.81). Conclusions: Caffeine in low doses produces a higher increase in the maximum strength of upper limb, followed by the maximum force of lower limb and favors a smaller increase in lactate levels.

Keywords: Caffeine; muscular strength; lactate; exercise. (Source: DeCS, Bireme).

\section{Introducción}

La cafeína es un alcaloide, considerada por la OMS como una droga estimulante del Sistema Nervioso Central, junto con las anfetaminas, nicotina y cocaína; cuyo efecto se centra en la reducción de la fatiga y en el aumento del estado de alerta, sin embargo la opinión sobre los beneficios del café siempre ha sido controversial ${ }^{1}$.

Las investigaciones realizadas en los últimos años han demostrado como el consumo de cafeína puede tener efectos sobre el rendimiento aeróbico y anaeróbico; por una parte se cree que puede desarrollar mayor fuerza isocinética; así mismo se considera su efecto sobre músculos sanos; pero no tendría ningún efecto en músculos dañados o lesionados 2 ; mientras otros estudios encontrados demuestran que el consumo de cafeína afecta la fuerza isométrica máxima y la resistencia muscular sobre el tren inferior del cuerpo; sin embargo lo referente a la fuerza isocinética, a la fuerza de una repetición máxima y la resistencia muscular de la musculatura del miembro superior son menos claros aún.

Durante el ejercicio el músculo puede desarrollar fatiga muscular y así mismo compromete la fuerza de contracción, la cual depende de la duración e intensidad del ejercicio con depleción del sustrato energético, del tipo de fibra muscular reclutada, del nivel de entrenamiento del sujeto y de las condiciones ambientales ${ }^{3-6}$. Son diversas las causas estudiadas para explicar la fatiga muscular, como las alteraciones del $\mathrm{pH}$, de la temperatura y del flujo sanguíneo; la acumulación de productos del metabolismo celular (especialmente de los que resultan de la hidrólisis del ATP, como el ADP, AMP, IMP, Pi y amonio), la pérdida de la homeóstasis del ion $\mathrm{Ca} 2+$, el papel de la cinética de algunos iones en los medios intra y extracelular (como el $\mathrm{K}+, \mathrm{Na}+, \mathrm{Cl}-\mathrm{Mg} 2+$ ), la lesión muscular (inducida por el ejercicio) y el stress oxidativo ${ }^{7}$; siendo la más conocida la teoría

del ión calcio, que se explica por la acumulación de Ca2+ en el sarcoplasma debido a que los ciclos de contracción repetitiva van disminuyendo su retorno a los depósitos, alterando la homeostasis del mismo; en este sentido la cafeína en altas concentraciones tiene un efecto directo aumentando la movilización de calcio del retículo sarcoplásmico (por desacoplamiento de la actividad ATPasa en el músculo esquelético) y la sensibilidad de los miofilamentos por el calcio, lo que produce una mayor excitabilidad de las fibras musculares, la cual mejora los mecanismos de contracción, aumenta la potencia, retrasa la aparición de fatiga y puede aumentar la fuerza y la duración de las contracciones del músculo esquelético.

Este mecanismo va ligado a la activación de las bombas $\mathrm{o}$ adenosintrifosfatasas de sodio $\mathrm{y}$ potasio (reducción del potasio plasmático durante el ejercicio), que se encargan del mantenimiento del gradiente electroquímico de las membranas celulares transportando sodio al interior celular y potasio al exterior de la célula ${ }^{8,9}$. Sin embargo, es poco probable que tenga un papel importante en las concentraciones terapéuticas ${ }^{9}$.

En este estudio se pretende demostrar si la ingesta aguda de cafeína produce cambios en la fuerza muscular máxima y en los niveles de lactato, pero no en deportistas, sino en población joven universitaria que no realiza ningún tipo de actividad física. La hipótesis que se plantea es que las variables estudiadas experimentarán una mejora tras la ingesta de cafeína, mientras que la cafeína placebo no producirá ningún beneficio. 


\section{Materiales y métodos}

\section{Diseño del estudio}

Se desarrolló un estudio ensayo clínico aleatorizado controlado de grupos paralelos ciego simple (participante), en donde se evaluó el efecto de la cafeína sobre la fuerza máxima y los niveles de lactato en sangre en una población de jóvenes universitarios sedentarios. La evaluación de la fuerza fue realizada por dos fisioterapeutas expertos con formación de maestría, mientras los niveles de lactato fueron calculados por parte de un laboratorio clínico con certificación de calidad.

\section{Población y muestra}

La muestra se calculó con una confianza del 95\% y una potencia del $80 \%$, con una diferencia esperada entre los grupos de 5 para la variable principal de fuerza máxima y una desviación de 6 , precisando un total de 20 sujetos para cada grupo, concordante con los estudios previos descritos en los antecedentes en donde la muestra no supera 20 personas por cada grupo ${ }^{9,12-14,}$, Los participantes fueron reclutados mediante aviso en boletín informativo de la institución universitaria donde se realizó el estudio. En total 43 sujetos cumplieron los criterios de inclusión, los cuales se asignaron de forma aleatoria, 23 jóvenes al grupo de ingesta de cafeína y 20 jóvenes al protocolo control sin cafeína, de los cuales el $91 \%$ eran mujeres y el $9 \%$ eran hombres (22.1 \pm 23.0 años).

Como criterios de inclusión se tomaron que los sujetos no fueran consumidores habituales de cafeína, sin patologías de base, sin sobrepeso, sin lesión muscular, sin entrenamiento de fuerza en tren superior y tren inferior en más de una vez por semana; se excluyeron sujetos con diagnóstico de arritmia cardiaca, insomnio, alteración hidroelectrolítica (Deshidratación por diarrea o vomito en los últimos días), insuficiencia respiratoria y convulsiones. Todo el procedimiento se llevó a cabo en el laboratorio de terapia física de la Universidad San Buenaventura de Cartagena, Colombia.

Todos los participantes dieron su consentimiento informado por escrito; los criterios de inclusión se tuvieron en cuenta para la formación de los grupos y así conformarlos de manejar homogénea. Los sujetos participaron de manera voluntaria, además recibieron explicación verbal del propósito de la investigación, el protocolo a seguir, los procedimientos experimentales y los riesgos asociados con el proyecto, además firmaron el consentimiento informado que había sido aprobado previamente por el Comité de Ética de la Universidad de San Buenaventura. Todos los procedimientos experimentales utilizados en el estudio se ajustaban a la consideración ética del Código Helsinki y la Resolución 08430 de 1993 del Ministerio de Salud de Colombia.

\section{Aleatorización}

Se realizó un procedimiento de aleatorización simple por bloques para la asignación de los sujetos al grupo con ingesta de cafeína real y al grupo sin cafeína; mediante un generador de números aleatorios el cual creó una secuencia de 100 asignaciones en el conocimiento de que no se reclutarían más de este número de participantes. La secuencia de asignación se ocultó al investigador; la cual fue entregada en sobres opacos sellados que contenían la asignación.

\section{Procedimiento}

Después de la aprobación por parte del Comité de Ética de la Universidad San Buenaventura, el tamaño de la muestra partió de 92 sujetos quienes se inscribieron en este estudio para ser elegidos entre octubre y diciembre de 2014, previa firma del consentimiento informado. El flujo de participantes se muestra en la figura 1, en total 43 sujetos que cumplieron los criterios de inclusión, todos (100\%) permanecieron durante el periodo de seis meses que duró el estudio, lo cual permitió conformar grupos homogéneos (varianza aproximada a 0 ).

Todos los sujetos fueron citados al laboratorio para la sesión inicial, donde se tomaron las medidas antropométricas, peso, talla, índice de masa corporal e índice cintura cadera. Después fue tomada muestra de sangre venosa en la vena antecubital; tomada en ayunas y sin haber realizado ninguna actividad muscular intensa, con la cual se determinó los niveles de lactato en sangre mediante espectrofotometría (Kit comercial Sigma) ${ }^{15}$. Luego, los participantes 
realizaron la evaluación de una repetición máxima (1RM) para miembro superior e inferior; pudiéndose realizar dichos test por medio de máquinas o pesos libres ${ }^{16}$; utilizando una prensa de piernas a $45^{\circ}$ (Precor 601, USA, Inc.) y press de banca (Precor 408, USA, Inc.). Todos los participantes terminaron los procedimientos y no se presentaron eventos adversos durante el desarrollo de las pruebas y la toma de muestra sanguínea.

El grupo experimental tomó una bebida energética de $240 \mathrm{ml}$ con un contenido de cafeína de $80 \mathrm{mg}$ (diluido en una bebida láctea para neutralizar el sabor), dosis inferior a la reportada en otros estudio en donde el promedio es de $6 \mathrm{mg} / \mathrm{kg}$ de peso, para este estudio la dosis promedio fue de $1,3 \mathrm{mg} / \mathrm{Kg}$ de peso (peso medio de los sujetos $60 \mathrm{Kg}$ ); esto representa la tercera parte de lo encontrado en la teoría y que la definen con el punto a partir de donde parecen incrementarse los efectos ergogénicos de la misma $^{10}$. El grupo control tomó placebo (bebida láctea sin cafeína). Durante el estudio experimental se supervisó por parte del equipo de investigación que los participantes tomaran la bebida en los tiempos y en la cantidad estipulada en el protocolo.

La segunda medida se tomó una horas después de la ingestión de cafeína o placebo, utilizando las mismas pruebas, tal como se realizó en la línea base. En total se tomaron dos muestras de sangre y se evaluó dos veces la fuerza máxima (1RM), tanto para miembro superior, como para miembro inferior durante el estudio.

\section{Grupos intervención}

Se realizó una única sesión de ingesta de cafeína o placebo en cada grupo. El evaluador era ciego a esta ingesta y tampoco se informó a los sujetos a qué grupo habían sido asignados.

\section{Grupo ingesta de cafeína}

Se aseguró que los sujetos permanecieran ciegos a la ingesta de cafeína con la dilución de la misma en una bebida láctea, la cual neutralizo el sabor. A cada sujeto le fue entregada la bebida en envase plástico limpio transparente sellado de $600 \mathrm{ml}$ ( $240 \mathrm{ml}$ bebida con cafeína incolora $+360 \mathrm{ml}$ de bebida láctea) sin etiquetas de ninguna clase para asegurar que tomaran todo el contenido, para ello se les dio cinco minutos para la ingesta y una hora de reposo para tomar la segunda medida de la fuerza máxima (1RM) y el lactato.

\section{Figura 1. Diagrama de flujo de los participantes del estudio}

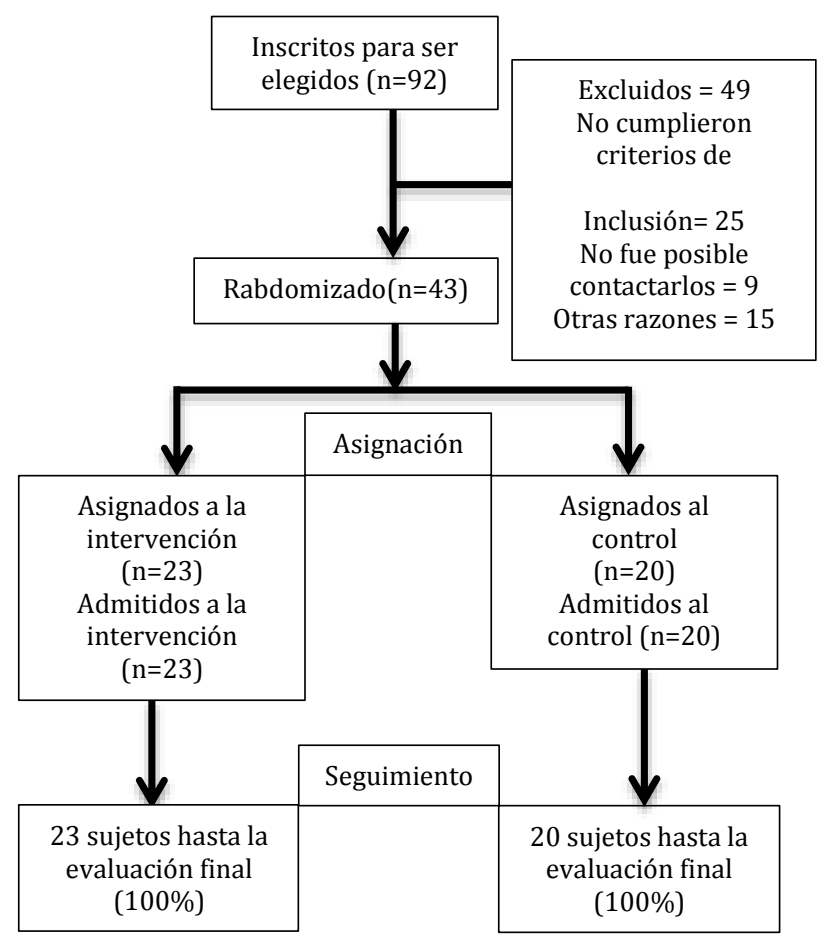

\section{Grupo ingesta placebo}

Los sujetos del grupo control se cegaron al procedimiento, se les dio a beber una bebida láctea entregada en envase plástico limpio transparente y sellado de $600 \mathrm{ml}$, de apariencia y características idénticas a las entregadas al grupo experimental, lo que permitió tener mejor control, el tiempo de ingesta fue de 5 minutos y posterior se dio un reposo de 1 hora para tomar la medida de fuerza (1RM) y de lactato.

\section{Medidas de resultado}

Todas las medidas primarias se tomaron al inicio del estudio y hora después de la ingesta de cafeína o placebo, mientras las medidas secundarias solo se tomaron al inicio del estudio y fueron administradas por el grupo de investigación principal. Las medidas primarias fueron: fuerza 
máxima (1RM) y niveles de lactato en sangre; las medidas secundarias fueron: peso, talla, índice de masa corporal e índice cintura cadera.

\section{Análisis estadístico}

Se realizó un análisis descriptivo e inferencial; el análisis descriptivo para las variables antropométricas se expresaron en media \pm desviación estándar; mientras el análisis inferencial buscó comparar los grupos. El Kolmogorov-Smirnov (K-S) confirmó la distribución normal de las variables; por lo tanto se utilizó la prueba paramétrica $\mathrm{T}$ de student para comparar las pruebas pre y pos ingestión de cafeína o placebo mediante las medias de las diferencias; seguido por la diferencia porcentual cuando se encontraron diferencias significativas entre la pre-prueba y la pos-prueba; además se utilizaron las medias y las desviaciones estándar para determinar el tamaño del efecto (TE) con la d-Cohens (es decir la diferencia de las dos medias dividida por la desviación estándar combinada) para determinar la magnitud de las diferencias en los puntajes de una prueba a otra y las diferencias entre grupos. (Tabla 2)

Con este se logró determinar qué tan grande fue el efecto de la variable independiente sobre las variables dependientes. Se consideró el nivel de significancia de $\mathrm{p}<0,05$. Todos los procedimientos estadísticos fueron realizados en el programa estadístico para las Ciencias Sociales (SPSS v.17 para Windows).

\section{Resultados}

En total 43 sujetos cumplieron los criterios de inclusión, de los cuales el $91 \%$ eran mujeres y el $9 \%$ eran hombres (22.1 $\pm 2,30$ años). La edad media en el grupo experimental y control fue de 22,1 años $( \pm 2,30)$ y $20,70 \quad( \pm 1,26)$ respectivamente; en el grupo experimental el 91\% de los participantes fueron mujeres, mientras que para el grupo control las mujeres fueron un $80 \%$; el peso promedio para el experimental fue $60,8 \mathrm{Kg}( \pm 12,66)$ y en el control fue de $59,15 \mathrm{Kg}( \pm 13,82)$, la media de la estatura en el experimental fue 1,61 metros $( \pm 0,01)$ y de 1,58 metros $( \pm 0,10)$ para el control, el índice de masa corporal estuvo en $23,33( \pm 3,64)$ para el experimental y de $23,40( \pm 3,64)$ para el control; el índice cintura cadera para el experimental y control fue de $0,74( \pm 0,05)$ y $0,69( \pm 0,04)$ respectivamente. (Tabla 1 )

Tabla 1. Características antropométricas de jóvenes universitarios del grupo experimental y control

\begin{tabular}{|c|c|c|c|c|}
\hline Variable & Grupo & $\begin{array}{c}\text { Frecuencias } \\
\text { (n) }(\%)\end{array}$ & Media & SD \\
\hline \multirow{2}{*}{$\begin{array}{l}\text { Edad } \\
\text { (años) }\end{array}$} & $\begin{array}{l}\text { Experimental } \\
(n=23)\end{array}$ & - & 22,10000 & 2,30 \\
\hline & $\begin{array}{l}\text { Control } \\
(n=20)\end{array}$ & - & 20,70 & 1,26 \\
\hline \multirow{2}{*}{$\begin{array}{l}\text { Sexo } \\
(M / F)\end{array}$} & $\begin{array}{l}\text { Experimental } \\
(\mathrm{n}=23)\end{array}$ & $2 / 21(8,7 / 91,3)$ & - & - \\
\hline & $\begin{array}{l}\text { Control } \\
(n=20)\end{array}$ & $4 / 16(20 / 80)$ & - & - \\
\hline \multirow{2}{*}{$\begin{array}{l}\text { Peso } \\
(\mathrm{Kg})\end{array}$} & $\begin{array}{l}\text { Experimental } \\
(\mathrm{n}=23)\end{array}$ & - & 60,86000 & 12,66 \\
\hline & $\begin{array}{l}\text { Control } \\
(n=20)\end{array}$ & - & 59,15 & 13,82 \\
\hline \multirow{2}{*}{$\begin{array}{l}\text { Estatura } \\
\text { (mts) }\end{array}$} & $\begin{array}{l}\text { Experimental } \\
(\mathrm{n}=23)\end{array}$ & - & 1,61 & 0,01 \\
\hline & $\begin{array}{l}\text { Control } \\
(n=20)\end{array}$ & - & 1,58 & 0,10 \\
\hline \multirow{2}{*}{$\begin{array}{l}\mathrm{IMC} \\
(\mathrm{Kg} / \mathrm{mt} 2)\end{array}$} & $\begin{array}{l}\text { Experimental } \\
(\mathrm{n}=23)\end{array}$ & - & 23,33000 & 3,16 \\
\hline & $\begin{array}{l}\text { Control } \\
(n=20)\end{array}$ & - & 23,40 & 3,64 \\
\hline \multirow{2}{*}{ ICC (\%) } & $\begin{array}{l}\text { Experimental } \\
(\mathrm{n}=23)\end{array}$ & - & 0,74 & 0,05 \\
\hline & $\begin{array}{l}\text { Control } \\
(n=20)\end{array}$ & - & 0,69 & 0,04 \\
\hline
\end{tabular}

El test de 1RM medido por la carga (Kg) máxima que el sujeto fue capaz de levantar en miembro superior y miembro inferior, se utilizó para evaluar la fuerza máxima; con el cual se pudo observar que para la evaluación inicial de $1 \mathrm{RM}$ de miembro superior $(31,7 \pm 10,3)$ y de miembro inferior $(35,8 \pm 15,9)$ fue superior en el grupo experimental, comparado con la $1 \mathrm{RM}$ de miembro superior $(28,2 \pm 5,1)$ y miembro inferior $(30,6 \pm$ 4,0 ) del grupo control (Tabla 2); mientras que posterior a la ingesta de cafeína se observó en el grupo experimental un incremento de la fuerza máxima para miembro superior de $40 \mathrm{~kg} \pm 15,1$; con una media de la diferencia de $8,3 \mathrm{Kg}(26,2 \%$; d efecto de Cohen 0,64) incremento 
estadísticamente significativo $(\mathrm{t}=-4,36 ; \mathrm{gl}=41$; p=0,000; IC: $-16,9$ a -6,2) y de la fuerza máxima para miembro inferior de 45,1 Kg \pm 19 ,9; con una media de la diferencia de $9,24 \mathrm{Kg}(25,8 \%$; d efecto de Cohen 0,51); que fue también estadísticamente significativo $(t=-3,16 ; g l=41 ; p=0,000 ; I C:-17,0$ a $-3,7)$; mientras que en el grupo control para miembro superior se observó una disminución significativa de la fuerza máxima de $27,15 \mathrm{Kg} \pm$ 15,83; con una media de la diferencia de $-1,05 \mathrm{Kg}$ $(-3,7 \%$; d efecto de Cohen $-0,19)$ y para miembro inferior existe un pequeño incremento pero significativo de la fuerza en $31,59 \pm 2,82$; con una media de la diferencia de $0,95 \mathrm{Kg}(3,1 \%$; d efecto de Cohen 0,27) (Tabla 3), con lo cual podemos inferir con una confianza del 95\% que el consumo de cafeína mejora la fuerza máxima de miembros superiores y de miembros inferiores.

Los niveles de lactato, fueron medidos en sangre antes y después de la ingestión de cafeína; en los cuales se encontró que en la evaluación inicial los valores de lactato en el grupo experimental 1,48 $\pm 0,23)$ fue similar que en el grupo control $(1,53 \pm$ 0,24 ) (Tabla 2); mientras que posterior a la ingestión de cafeína se observó en el grupo experimental un aumentó en la media del lactato de $2,44 \mathrm{mmol} / \mathrm{L} \pm 0,25$; con una media de la diferencia de $0,96 \mathrm{mmol} / \mathrm{L}$ (64,9\%; d efecto de Cohen 3,99); este incremento fue estadísticamente significativo $(\mathrm{t}=10,8 ; \mathrm{gl}=41$; $p=0,000$; IC: 0,55 a 0,81 ); mientras en el grupo control también se pudo observar un aumento de $3,13 \pm 0,13$; con una media de la diferencia de 1,6 mmol/L (104,6\%; d efecto de Cohen 8,48); (Tabla 3 ); aunque fue superior el incremento del grupo control. Con esto se puedo afirmar con una confianza del 99\% ( $p=0,000)$ que la cafeína tiene efecto control sobre los niveles de lactato, permitiendo que en el grupo experimental su ascenso fuera menor que en los del grupo control.

Tabla 2. Media y desviación estándar de las diferencias para la prueba inicial y prueba final en el grupo experimental y control

\begin{tabular}{|c|c|c|c|c|c|c|}
\hline Variable & Grupo & $\begin{array}{c}\text { Prueba inicial } \\
\text { (Media } \pm \text { DE) }\end{array}$ & $\begin{array}{l}\text { Prueba final } \\
\text { (Media } \pm \text { DE) }\end{array}$ & $\begin{array}{c}\text { Diferencia } \\
\text { (Media } \pm \text { DE) }\end{array}$ & p-valor & IC \\
\hline \multirow{3}{*}{ Lactato $(\mathrm{mmol} / \mathrm{L})$} & Experimental & $1,48(0,23)$ & $2,44(0,25)$ & $0,96(0,10)$ & \multirow{3}{*}{$0,000^{\beta}$} & \multirow{3}{*}{$-0,72$ a $-0,55$} \\
\hline & Control & $1,53(0,24)$ & $3,13(0,13)$ & $1,59(0,17)$ & & \\
\hline & Control & $15,78(3,08)$ & $15,52(1,81)$ & $-0,26(1,71)$ & & \\
\hline \multirow{2}{*}{ Total 1RM_MS (Kg) } & Experimental & $31,7(10,3)$ & $40(15,1)$ & $8,3(6,0)$ & \multirow{2}{*}{$0,000^{\beta}$} & \multirow{2}{*}{6,0 a 12,6} \\
\hline & Control & $28,2(5,12)$ & $27,15(5,83)$ & $-1,05(4,51)$ & & \\
\hline \multirow{2}{*}{ Total 1RM_MI (Kg) } & Experimental & $35,88(15,9)$ & $45,12(19,9)$ & $9,24(4,9)$ & \multirow{2}{*}{$0,000^{\beta}$} & \multirow{2}{*}{5,6 a 10,9} \\
\hline & Control & $30,64(4,02)$ & $31,59(2,82)$ & $0,95(3,589$ & & \\
\hline
\end{tabular}

$\beta$ Diferencias estimadas con la Prueba T Student para muestras independientes.

Tabla 3. Valores de lactato, fuerza máxima antes y después de la ingestión de cafeína y placebo

\begin{tabular}{lrrrrrr}
\hline & \multicolumn{2}{c}{ Valor lactato (SD) } & \multicolumn{2}{c}{ Fuerza máxima MS (SD) } & \multicolumn{2}{c}{ Fuerza máxima MI (SD) } \\
& Control & Experimental & \multicolumn{1}{c}{ Control } & Experimental & Control & \multicolumn{1}{c}{ Experimental } \\
\hline Antes de la ingestión & $1,53(0,24)$ & $1,48(0,23)$ & $28,2(5,12)$ & $31,7(10,3)$ & $30,64(4,02)$ & $35,88(15,9)$ \\
Después de la ingestión & $3,13(0,13)$ & $2,44(0,25)$ & $27,15(5,83)$ & $40(15,1)$ & $31,59(2,82)$ & $45,12(19,9)$ \\
Tamaño del efecto & 8,48 & 3,99 & $-0,19$ & 0,64 & 0,27 & 0,51 \\
Cambio promedio \% & 104,6 & 64,9 & $-3,7$ & 26,2 & 3,1 & 25,8 \\
\hline
\end{tabular}

Nota: Valores expresados en Media \pm SD 


\section{Discusión}

La ganancia de fuerza máxima fue significativamente superior después de la ingesta de cafeína, esto se puede explicar por el efecto que la cafeína tiene sobre los niveles de calcio en el retículo sarcoplásmico (RS); aunque estudios han demostrado que la administración in vivo de la cafeína en roedores puede causar la liberación de calcio desde el RS a través de los receptores de Ryanodine que actúan como mediadores celulares de la liberación de calcio (inducida por calcio) del SR y puede aumentar la fuerza ${ }^{17}$.

Sin embargo, en los seres humanos, la dosis de cafeína necesaria para producir un efecto similar sería toxico ${ }^{18}$. Por lo tanto, en los seres humanos, puede ser el caso de que los efectos ergogénicos de la cafeína se producen al actuar sobre el sistema nervioso en lugar de directamente sobre el músculo esquelético en los mecanismos de excitación-contracción; aunque se requieren más estudios.

Un hallazgo importante de este estudio es que se pudo demostrar que con la ingestión de una dosis baja de cafeína, se alcanzó un aumento del 26,2\% de la fuerza máxima de miembro superior $(8,3 \mathrm{Kg}$; $\mathrm{p}=0,001$ ) y del $25,8 \%$ de la fuerza máxima en miembro inferior $(9,24 \mathrm{Kg} ; \mathrm{p}=0,004)$. La magnitud de este efecto es diferente con lo encontrado en otros estudios que examinaron la influencia de la cafeína sobre la fuerza muscular en humanos; encontrando seis estudios que miden fuerza del tren inferior, donde la dosis de cafeína ( 4 a 7 mg X kg-1); el suministro de una hora antes de las pruebas y la historia reciente de uso (bajo consumo de cafeína) fueron similares con este estudio. A diferencia de los resultados de este estudio, cinco de los seis estudios dieron lugar a pequeñas mejoras en la fuerza voluntaria máxima, con un promedio de tan solo el $4 \%$ de incremento con una media entre el 3 al 5\% ${ }^{18-23}$.

Estudios concluyen que la cafeína a dosis pequeñas no ejerce ningún efecto ergogénico sobre la función muscular en condiciones anaeróbicas ${ }^{19}$; mientras en otro estudio se encuentra que a una dosis de $7 \mathrm{mg} \mathrm{kg}-1$ la fuerza aumenta por la ingestión de cafeína ${ }^{21}$, a dosis de
$6 \mathrm{mg} / \mathrm{Kg}$ el aumento en la fuerza máxima es de $3,5 \%$ sin cambios en el reflejo $\mathrm{H}$, concluyendo los autores que la cafeína actúa tanto periféricamente, como de forma supraespinal ${ }^{18}$. En otro estudio la fuerza máxima se incrementó en un 3,8\% ${ }^{22}$ y finalmente otro estudio encontró a una dosis de $6 \mathrm{mg} / \mathrm{Kg}$ un cambio en la fuerza equivalente al $17 \%$ y concluyen que el efecto de la cafeína esta sobre la reducción de la sensación de fuerza ${ }^{23}$.

El aumento de la fuerza después de la ingestión de cafeína podría estar relacionado con la síntesis muscular endógena del óxido nítrico (NO); como lo pudo demostrar Corsetti Giovanni, et al., quienes evaluaron la expresión del NOS y Bcl2 en los músculos esqueléticos de ratas después de la administración de cafeína aguda. Llegando a la conclusión que la mejora del rendimiento físico podría estar relacionada con la capacidad de la cafeína para interferir con la síntesis muscular endógena del NO, ocasionando mejora el rendimiento muscular y evita daños sobre éste ${ }^{24}$.

Esto se explica mediante la teoría que indica que la cafeína aumenta la inhibición de la fosfodiesterasas mediada por el GMP cíclico (cGMP) y AMP cíclico (cAMP). Así, la elevación citosólica de cGMP y cAMP induce varias modificaciones bioquímicas que influyen en el metabolismo del calcio y de manera interesante en el metabolismo del óxido nítrico (NO) ${ }^{24}$, que sugieren otros estudios encontrados que demuestran que la cafeína $(0,5$ a $16 \mathrm{mg} / \mathrm{kg})$ aumenta significativamente la actividad locomotriz al modular el óxido nítrico ${ }^{25}$.

Los anteriores efectos parecen deberse al incremento intracelular de calcio y a la activación de las bombas de sodio/potasio, que facilitan la disminución del tiempo de reacción en los individuos ${ }^{26}$. Sin embargo, dos estudios recientes no encuentran ningún efecto ergógeno de la cafeína en la fuerza muscular ${ }^{26}$.

El lactato es un intermediario metabólico que aumenta durante el ejercicio de alta intensidad, como consecuencia de la elevada actividad glicolítica. En esas condiciones la formación de ATP se asocia con generación de iones lactato e 
$\mathrm{H}+\mathrm{y}$ se reduce el $\mathrm{pH}$ de la célula activa. Si hay fatiga, el aumento en los niveles de lactato se correlaciona con la magnitud en la caída de la fuerza y los niveles de lactato alcanzados a un determinado nivel de actividad dependen del tipo de la fibra muscular. La salida de lactato de la fibra ocurre principalmente por tres mecanismos de los cuales el más importante es el co-transporte acoplado de lactato-H+, cuya actividad depende del tipo de fibra y del patrón de activación así como del $\mathrm{pH}$ y de la concentración del amortiguador (buffer) externos ${ }^{27}$.

En este estudio las medidas del lactato después de la ingestión de cafeína se elevaron en ambos grupos, pero fueron menores los incrementos en el grupo experimental $(0,96 \mathrm{mmol} / \mathrm{L}, \mathrm{p}=0,000)$ comparadas con la del grupo control $(1,6 \mathrm{mmol} / \mathrm{L}$, $\mathrm{p}=0,000$ ), lo que muestra que probablemente la cafeína tiene alguna influencia sobre la concentración plasmática del lactato; lo que difiere con el estudio de Duncan Michael J y Hankey Joanne, realizado en ciclismo, quienes encontraron que la concentración de lactato después de la ingestión de cafeína fue mayor ( $p=0,002 ; p=0,0001 ; p=0,021)$, lo que indica que los sujetos se sienten con menos fatiga y existe una disposición a invertir el esfuerzo durante la prueba $^{28}$.

Otros autores encontraron que el lactato tuvo un incremento superior en el grupo con cafeína sustentado por el aumento de la disponibilidad de ácidos grasos libres que reducen la producción de lactato y su utilización; por lo cual el metabolismo del piruvato debe ocurrir rápidamente; además ha comentado que la cafeína puede inhibir la oxidación de piruvato y a su vez, la utilización de lactato, pero aumenta la producción del mismo ${ }^{29}$.

El incremento de lactato que se dio en el grupo control es la explicación más clara de por qué el ejercicio de contracción isocinética aumenta el lactato, debido a que éste logra la acumulación de lactato también en los músculos involucrados en las actividades evaluadas, además causan una disminución del $\mathrm{pH}$ intracelular. Esto a su vez altera las propiedades contráctiles del músculo y la actividad de las enzimas glucogenolíticos ${ }^{30}$.
Aunque estos resultados son contradictorios con los del grupo experimental, en donde el lactato no tuvo incrementos significativos, demostrados en nuestro estudio en donde el rendimiento muscular es mayor; por esta razón se debe sustentar desde otra óptica; por ejemplo Bridge y Jones sugieren que una teoría alternativa puede ser que la cafeína promueve el aumento de la resíntesis del ATP a través de la glucólisis anaeróbica que permite la provisión de energía más rápida por aumento de la actividad de la fosfofructoquinasa o un mayor flujo de salida de $\mathrm{H}+$ de la célula muscular con los valores de lactato en sangre posteriores para una determinada carga de trabajo en el presencia de cafeína ${ }^{30}$.

Algunos autores aseguran que en ejercicios anaeróbicos (15 a 30 minutos) la cafeína no parece tener ningún efecto positivo, posiblemente debido al incremento de las concentraciones de lactato, que disminuyen el $\mathrm{pH}$ intracelular y reducen el rendimiento ${ }^{30}$. Mientras que el mecanismo de acción de la cafeína se debería principalmente a la activación de la fuerza muscular y al aumento de la contracción, mediante los mecanismos directos sobre el músculo y al descenso de la acumulación del potasio extracelular que se da como consecuencia del ejercicio.

Existen algunas limitaciones de los resultados de la presente investigación; el uso de una pequeña muestra de jóvenes que consumen cafeína de forma aguda, la mayoría fueron mujeres sanas. El efecto sobre la fuerza y la resistencia observada con el consumo de una única dosis de $80 \mathrm{mg}$ de cafeína no se pueden generalizar a otras muestras; probablemente es porque muchos de los efectos son dependientes de la dosis de cafeína; una aplicación con diferentes dosis de cafeína habría permitido una mayor generalización. El tamaño o magnitud del efecto también puede ser dependiente de la dosis de cafeína.

Se desconoce si dosis de cafeína más pequeñas o más grandes producirían menores, iguales o mayores efectos sobre fuerza muscular. En el presente estudio se pudo determinar que el consumo de cafeína en pequeñas dosis, puede 
producir grandes resultados en la fuerza muscular y retardan la elevación de los niveles de lactato y retardar la aparición de la fatiga.

En síntesis, que el consumo de cafeína en dosis bajas, $80 \mathrm{mg}$ de dosis única $(1,3 \mathrm{mg} \times \mathrm{Kg}$ ) incrementa la fuerza máxima isocinética (test de 1RM) de miembros superiores y de miembros inferiores; siendo superior en el tren superior. Mientras que el lactato se vio incrementado en los dos grupos, pero en menor proporción cuando se consumió la cafeína. Se necesitaran más estudios que demuestren de que forma la cafeína en un consumo agudo puede impactar en la fuerza máxima, medida por el test de $1 \mathrm{RM}$. La ingestión de cafeína puede ser una ayuda eficaz para mejorar la fuerza en adultos jóvenes sanos; es posible que puede ser utilizado como ayudante en los procesos de rehabilitación, que involucren trabajos de fuerza; pero se necesita ampliar los estudios hacia población no sana.

Fuente de financiamiento: Este proyecto fue financiado en su totalidad por el grupo investigador.

Conflicto de interés: Los autores declaran no tener ningún conflicto de interés.

\section{Referencias}

1. Turley KR, Rivas JD, Townsend JR, Morton AB, Kosarek JW, Cullum MG. Effects of caffeine on anaerobic exercise in boys. Pediatr Exerc Sci. 2012;24(2):210-9.

2. Davis JK, Green JM. Caffeine and anaerobic performance: ergogenic value and mechanisms of action. Sports Med. 2009;39(10):813-32.

3. American College of Sports Medicine (US). ACSM's resource manual for guidelines for exercise testing and prescription. 5th ed. Baltimore, MD: Lippincott Williams \& Wilkins; 2005.

4. Enoka R, Stuart D. Neurobiology of muscle fatigue. J Apll Physiol. 1992;72(5):1631-48.

5. Poortmans JR. Principals of exercise biochemistry. $3^{\text {rd }}$ ed. Basel; New York: Karger, 2004.

6. Roberts D, Smith D. Biochemical aspects of peripheral muscle fatigue - a review. Sports Med. 1989;7:125-38.

7. Ascensão A, Magalhães J, Oliveira J, Duarte J, Soares J. Fisiologia da fadiga muscular. Delimitação conceptual, modelos de estudo e mecanismos de fadiga de origem central e periférica. Revista Portuguesa de Ciências do Desporto. 2003;3(1):108-23.
8. Fimland MS, Helgerud J, Knutsen A, Ruth H, Leivseth G, Hoff J. No effect of prior caffeine ingestion on neuromuscular recovery after maximal fatiguing contractions. Eur J Appl Physiol. 2010;108(1):123-30.

9. Meyers BM, Cafarelli E. Caffeine increases time to fatigue by maintaining force and not by altering firing rates during submaximal isometric contractions. J Appl Physiol. 2005;99(3):1056-63.

10. Pasman WJ, Van Baak MA, Jeukendrup AE, DE Hann A. The effect of diferent dosages of caffeine on endurance performance time. Int J Sports Med, 1995;16(4):225-30.

11. Momsen $\mathrm{AH}$, Jensen $\mathrm{MB}$, Norager $\mathrm{CB}$, Madsen MR, Vestersgaard-Andersen T, Lindholt JS. Randomized double-blind placebo-controlled crossover study of caffeine in patients with intermittent claudication. $\mathrm{Br}$ J Surg. 2010;97(10):1503-10.

12. Park ND, Maresca RD, McKibans KI, Morgan DR, Allen TS, Warren GL. Caffeines enhancement of maximal voluntary strength and activation in uninjured but not injured muscle. Int J Sport Nutr Exerc Metab. 2008; 18(6):639-52.

13. Park JK y cols. Regulation of membrane excitability by intracellular $\mathrm{pH}(\mathrm{pHi})$ changers through $\mathrm{Ca} 2+$-activated $\mathrm{K}+$ current (BK channel) in single smooth muscle cells from rabbit basilar artery. Pflugers Arch. 2007; 454(2):307-19.

14. Norager CB, Jensen MB, Madsen MR, Laurberg S. Caffeine improves endurance in 75-yr-old citizens: a randomized, double-blind, placebo-controlled, crossover study. J Appl Physiol. 2005;99(6):2302-6.

15. Dobrocky P, Bennett PN, Notarianni LJ. Rapid method for the routine determination of caffeine and its metabolites by high-performance liquid chromatography. Journal of Chromatography B. 1994;652:104-08.

16. Bosco C. La valoración de la fuerza con el test de Bosco. Barcelona: Paidotribo; 1994.

17. Herrmann-Frank A, Luttgau HC, Stephenson DG. Caffeine and excitation-contraction coupling in skeletal muscle: A stimulating story. J Muscle Res Cell Motil. 1999;20:223-37.

18. Kalmar JM, Cafarelli E. Effects of caffeine on neuromuscular function. J Appl Physiol. 1999 87:801-08

19. Bond V, Gresham K, McRae J, Tearney RJ: Caffeine ingestion and isokinetic strength. Br J Sports Med. 1986 20:135-37.

20. Jacobsen BH, Edwards SW. Influence of two levels of caffeine on maximal torque at selected angular velocities. J Sports Med Phys Fitness. 1991;31:147-53.

21. Jacobsen BH, Weber MD, Claypool L, Hunt LE. Effect of caffeine on maximal power in elite male athletes. Br J Sports Med. 1992;26:276-80.

22. Lanigan C, Howes TQ, Borzone G, Vianna LG, Moxham J. The effects of beta 2-agonists and caffeine on respiratory and limb muscle performance. Eur Respir J. 1993;6:1192-96.

23. Plaskett CJ, Cafarelli E. Caffeine increases endurance and attenuates force sensation during submaximal isometric contractions. J Appl Physiol. 2001;91:1535-44.

24. Corsetti G, Pasini E, Assanelli D, Saligari E, Adobati M, Bianchi R. Acute caffeine administration decreased NOS 
and Bcl2 expression in rat skeletal muscles. Pharmacological Research. 2007;55:96-03.

25. Kayir H, Uzbay IT. Evidence for the role of nitric oxide in caffeine induced locomotor activity in mice. Psychopharmacology. 2004;172(1):11-5.

26. Nieves-Palacios GA, Iglesias-Gutiérrez E, Úbeda-Martín $\mathrm{N}$. Efecto de la cafeína en el rendimiento deportivo. Med Clin. 2008;131(19):751-5.

27. Giraldo-T JC, Sánchez ME. El lactato como posible factor del mecanismo de fatiga muscular. Colombia Médica. 1998;29(3):87-91.

28. Duncan MJ, Hankey J. The effect of a caffeinated energy drink on various psychological measures during submaximal cycling. Physiology \& Behavior. 2013;116(117):60-5.

29. Graham T. Caffeine and exercise: metabolism, endurance and performance. Sports Med. 2001;31:785807.

30. Bridge $\mathrm{C}$, Jones $\mathrm{MA}$. The effect of caffeine ingestion on 8 $\mathrm{km}$ run performance in a field setting. J Sports Sci. 2006; 24:433-9. 